\title{
Design and experimental studies of a novel circularly polarized antenna
}

\author{
Hai ZHANG ${ }^{a}$, Wei Guo ZHANG and Yue He GE \\ College of Information Science and Engineering, Huaqiao University, Xiamen 361021, China
}

\begin{abstract}
A circularly polarized antenna with patches on the top is studied in this paper. The antenna is composed of two printed dipoles and four radiation patches which are loaded on top of the dipoles. The antenna is fed by microstrip balum in the middle of dielectric slab. And the balum is connected to a Wilkinson power divider which owns 90 degree phase shift. Numerical simulations of proposed antenna are performed using the $3 \mathrm{D}$ electromagnetic simulation software HFSS. The experimental studies of the antenna are also carried out. Measured results show that the parameter S11 is less than $-10 \mathrm{~dB}$ from $1.1 \mathrm{GHz}$ to $1.8 \mathrm{GHz}$ while the $3 \mathrm{~dB}$ axial ratio bandwidth is from $1.27 \mathrm{GHz}$ to $1.62 \mathrm{GHz}$. The highest gain of $5 \mathrm{dBi}$ can be achieved during the operating frequencies.
\end{abstract}

\section{Introduction}

Circularly polarized (CP) micro-strip antenna has became one of the hottest research field of communication by its advantages, such as, small volume, light weight, simple construction, strong anti-interference capacity, tractable and so on. In recent years, the GPS and BD system have been used into military and civil communication fields extensively, while CP antennas are the important part of these systems. The frequency band of GPS contains L1 (1575.42 MHz), L2 (1227.6 MHz), L3 (1381.05 MHz), and E5a (1164 1189MHz), E5b (1189 1214 MHz) which belong to the European Galileo navigation system [1]. The frequency band of BD system contains L1 (1602 MHz), L2 (1246 MHz), B1 (1561 MHz), B2 (1207 $\mathrm{MHz}$ ). With the further research of $\mathrm{CP}$ antennas, how to realize broad axial ratio has became a research hotspot. The methods of realizing CP antennas have trend towards diversify. Slotting a strip slot on the surface of patch antenna can realize circularly polarized [2-4]. We can obtain high gain using horn antenna, but its size is too big and it is difficult to process [5]. By using single feed patch to design $\mathrm{CP}$ antenna is easy to process, but its bandwidth was narrow [6]. By using circle structure to realize $\mathrm{CP}$, its structure is simple. However, it also can't obtain ideal bandwidth [7,8]. In addition, there are L strip antennas [9], dual-band CP antenna [10], and double cross patch antenna [11] .Some scholars have proposed using broadband $\mathrm{CP}$ antenna to cover many bands of GPS system [12]. Therefore the broadband CP antennas that can cover part of the communication bands of GPS system are designed in this paper.

The unit of CP antenna are designed by combining the two double polarization printed antenna elements, and this structure has good bandwidth and good isolation [13, 14] .There are four vertical radiation patches on the top of

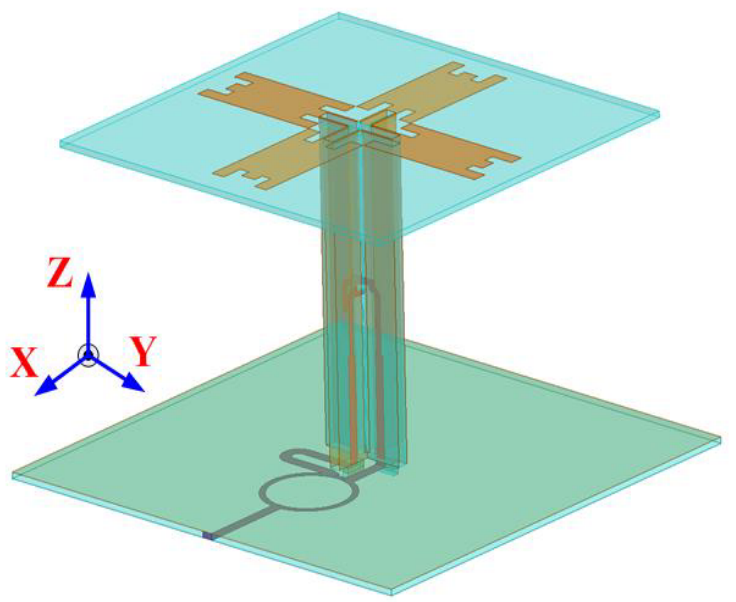

Figure 1. Simulation model of $\mathrm{CP}$ antenna

the antenna. And the antenna is fed by the one Wilkinson micro-strip power divider which has $90^{\circ}$ port phase shift on the bottom of the antenna. The printed power divider has many advantages such as simple structure, easy processing, and so on, such it is always used as feed network to feed small antennas. In this paper, the power divider has been printed on the bottom of the baffle-board. It can feed the antenna more simply, and has no-increase of the antenna size, while it can realize the broadband circularly polarization.

\footnotetext{
a Hai ZHANG: xjtuzhanghai@163.com .
} 


\section{Simulation study of CP antenna}

In this section, the simulation model of CP antenna is shown in figure 1 . It can be found that the two linear polarizations which have constant amplitude and the phase difference of $90^{\circ}$ can produce circular polarized wave. So in this paper, the halving feed network which has the phase difference of $90^{\circ}$ was used to feed the unit of antenna. By emulating and optimizing process, the antenna can possess the wide-band characteristics and is also stable. Designing CP antenna on this basis can effectively expand the axis ratio bandwidth of $\mathrm{CP}$ antenna and can make the radiation pattern of the antenna stable. The structure of the antenna in this paper has been shown in figure 2(dual polarized printed elements).

This antenna unit is composed of two double-sided printing vibrators with $90^{\circ}$ phase difference. In the actual design, the double-sided printing vibrator is composed of two dielectric-slabs added together, and it is fed by the micro strip Balun in the middle of it. The Balun feedings two vibrators have different height, and the slots were shaped on the bottom and top of two vibrators PCB. In this way, the two linear polarized vibrators can decussate together and realize the double polarization performance. There are four horizontal metal strips on the top. The antenna was designed using the $3 \mathrm{D}$ simulation software HFSS and the structure of the antenna is constructed as followed. The double-sided printing elements decussate together and the antenna is fed by the two J type Balums.

On the top of antenna, there is a dielectric-slab with the single sided printed metal strips. A cross bath that is used to package the antenna was slotted in the middle, and the top pastern is shorted with double-sided printed elements. The optimized size of the antenna is shown in table 1 .

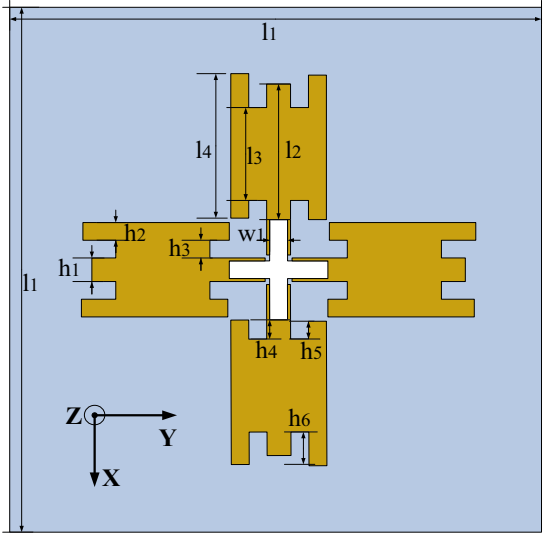

(a) The top loaded paches

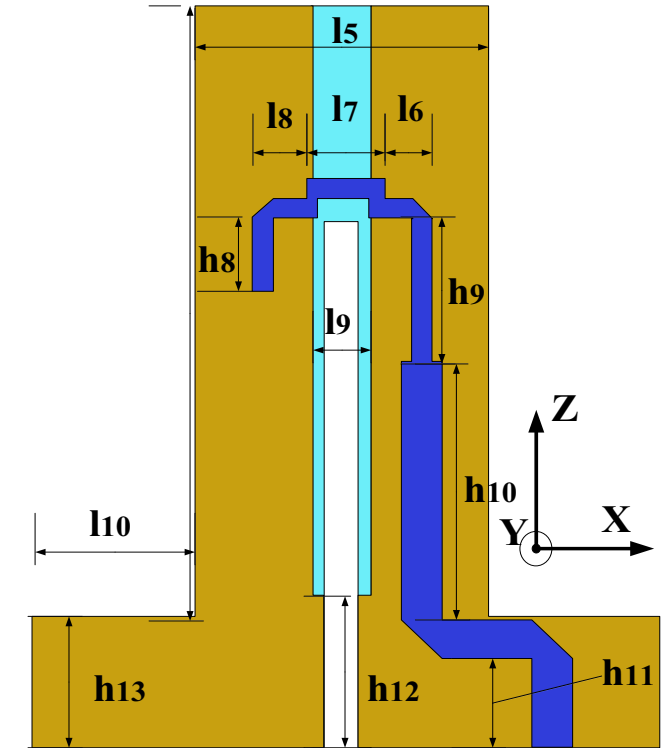

(b) Slot on the bottom

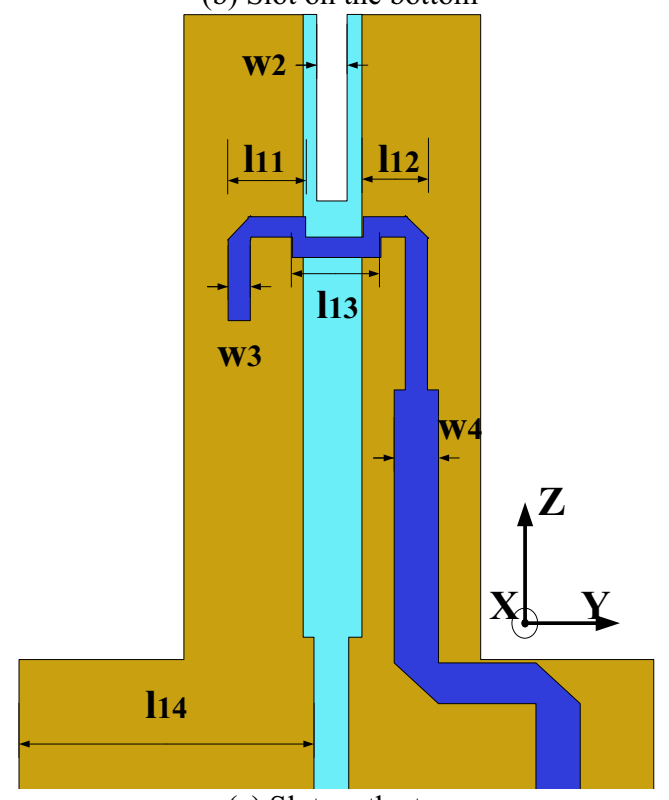

(c) Slot on the top

Figure 2. Structures of $\mathrm{CP}$ antenna with top patches

According to the design purpose, the antenna need to meet that the VSWR is less than 1.5 in $1.1 \sim 1.7 \mathrm{GHz}$ and the isolation of the two ports need to be less than $-20 \mathrm{~dB}$ in the bandwidth. When the design of the antenna has reached the standard, we can design the antenna by adjusting the feeding port on this basis. By using the 3D simulation software HFSS to simulate this structure, the simulation results are shown in figure 3 . It can be seen that the VSWR of the antenna is less than 1.5, and the bandwidth can cover 1.1 2.0 GHz. The isolation of the two ports is less than $-30 \mathrm{~dB}$ shown in figure 4 .

Table 1. Parameters of the antenna. (unit: $\mathrm{mm}$ )

\begin{tabular}{|c|c|c|c|}
\hline Parameters & Value & Parameters & Value \\
\hline 11 & 110 & h1 & 4.5 \\
\hline 12 & 31.5 & h2 & 4 \\
\hline
\end{tabular}




\begin{tabular}{|c|c|c|c|}
\hline 13 & 20 & $\mathrm{~h} 3$ & 3 \\
\hline 14 & 38 & $\mathrm{~h} 4$ & 6 \\
\hline 15 & 25 & $\mathrm{~h} 5$ & 9 \\
\hline 16 & 2.2 & $\mathrm{~h} 6$ & 9 \\
\hline 17 & 7 & $\mathrm{~h} 7$ & 81.6 \\
\hline 18 & 3.6 & $\mathrm{~h} 8$ & 7 \\
\hline 19 & 5 & $\mathrm{~h} 9$ & 15 \\
\hline 110 & 17.5 & $\mathrm{~h} 10$ & 27 \\
\hline 111 & 4.6 & $\mathrm{w} 1$ & 3.2 \\
\hline 112 & 3.2 & $\mathrm{w} 2$ & 3.2 \\
\hline 113 & 7 & $\mathrm{w} 3$ & 1.4 \\
\hline
\end{tabular}

amplitude of the two feeding port of a CP antenna are equal as well as the phase difference between the two port is 90 degree. Therefore, a bisection of microstrip power divider has been used, which has a 90deg phase difference between the two feeding port.

\section{Experimental study of CP antenna}

The proposed CP antenna which has four patches on the top is shown in figure 5. It is machined by the substrate FR4 with thickness of $1 \mathrm{~mm}$. We use vector network analyzer to test the matching impedance, and the result is shown in figure 6.

The results of simulation and measurement are shown from figure 7 to figure 9, the output port and the input port of feeding networks is connected. As shown in figure 14, during $1 \mathrm{GHz}$ and $2 \mathrm{GHz}$, the simulated s11 is lower than $-10 \mathrm{~dB}$, while the bandwidth of the measured result is from $1.1 \mathrm{GHz}$ to $1.8 \mathrm{GHz}$. Figure 8 shows the bandwidth corresponding to the AR below $3 \mathrm{~dB}$. The simulation results are from $1.15 \mathrm{GHz}$ to $1.68 \mathrm{GHz}$, while the measured bandwidth is from $1.27 \mathrm{GHz}$ to $1.62 \mathrm{GHz}$, about $24 \%$. Figure 9 showed the gain of the antenna.

The measurement was conducted in our microwave anechoic chamber. The antenna was fixed on the rotating platform, while one standard horn antenna was fixed one the other side. After processing the received signal we can achieve the measured results. The simulated results agree well with the measured results. The bandwidth of AR below $3 \mathrm{~dB}$ is from $1.27 \mathrm{GHz}$ to $1.62 \mathrm{GHz}$ (about $24 \%$ ), and the bandwidth of s11 below $-10 \mathrm{~dB}$ is from $1.1 \mathrm{GHz}$ to $1.8 \mathrm{GHz}$. The peak gain is $5 \mathrm{dBi}$.

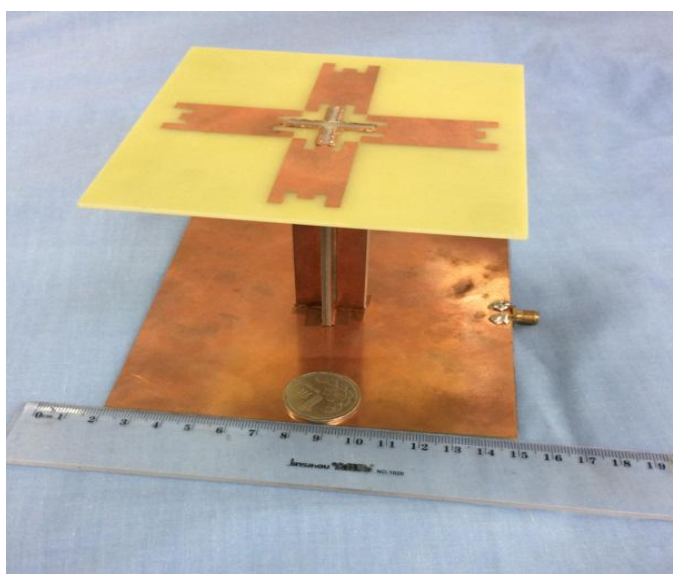

Figure 5. Photo of antenna

Figure 4. Reflection coefficient and isolation of antenna

\section{Design of feeding network}

It is a common way to use feeding network in CP antenna design. In the design, only one port act as the feeding port, and the signal reach the feeding port though the feeding network, which can reduce the design cost, simplify the structure, and the test and application will be easy. Considering about the bandwidth of the antenna in the context, we use a first order Wilkinson power divider to realize a circular polarization. We all know that the 


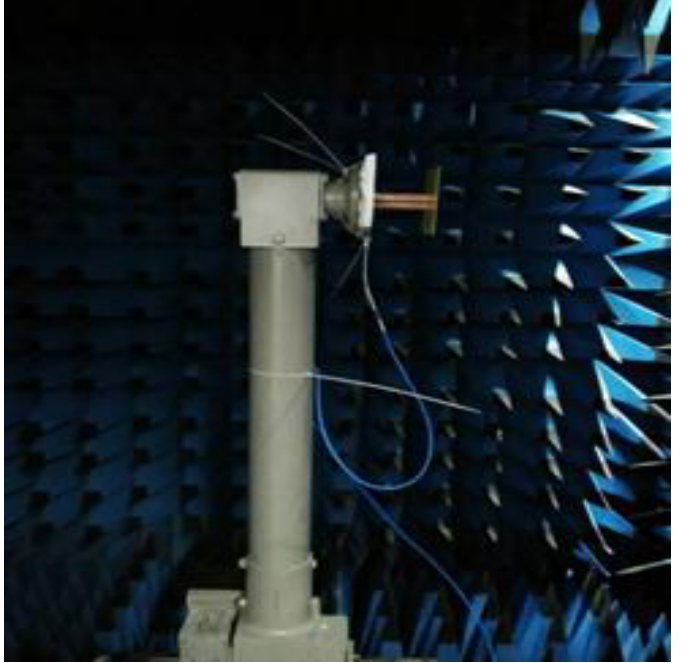

Figure 6. Photo of test equipment

\section{Conclusions}

The proposed CP antenna is made up of double sided printed dipoles, which is fed by a power divider network. Four radiation patches are loaded on top of the dipoles. The antenna is fed by a splitter located at the bottom of antenna. Both simulation and experimental studies are carried out, and the experimental results shown that the 3 $\mathrm{dB}$ axial ratio bandwidth of the antenna is from $1.27 \mathrm{GHz}$ to $1.62 \mathrm{GHz}(24 \%)$ and the highest gain can be up to 5 $\mathrm{dBi}$ within the operating frequency range. The antenna has good radiation performance.

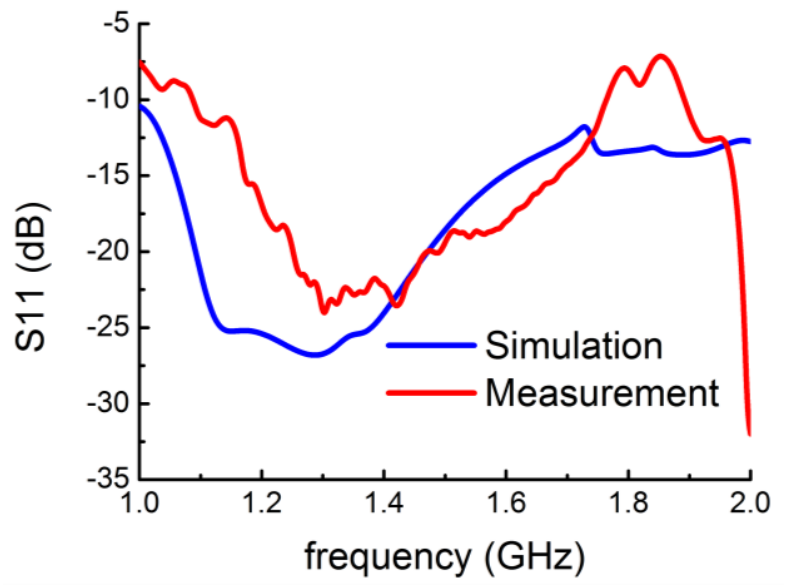

Figure 7. Simulated and measured results of S11

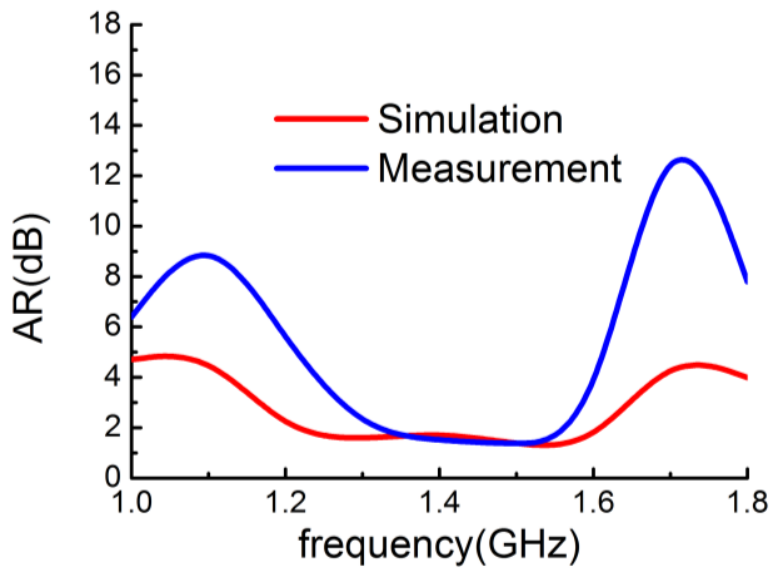

Figure 8. Simulated and measured results of AR

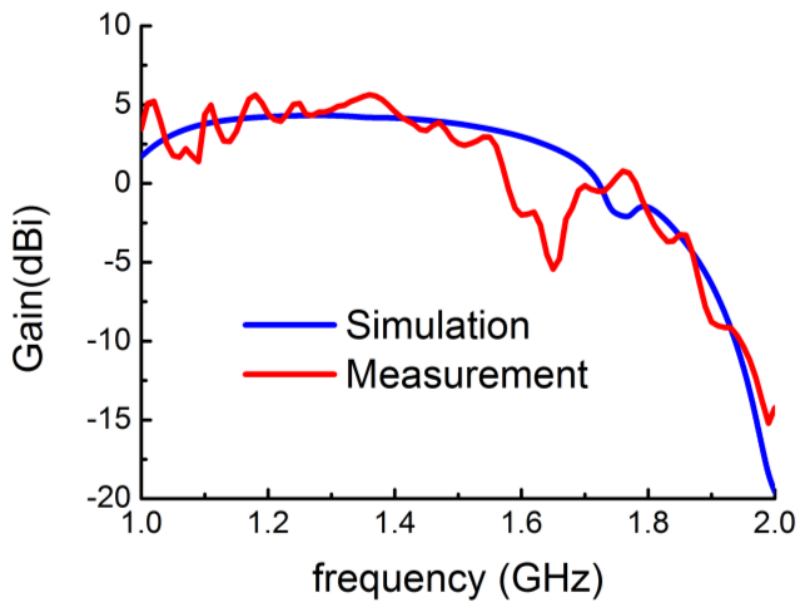

Figure 9. Simulated and measured results of gain

\section{Acknowledgments}

This work was supported by the Project of Education Department of Fujian Province, China (Grant No. JA14022), and the Undergraduate Education \& Teaching Reform Project of Huaqiao University, China (Grant No.2013JGYB36), Xiamen, Fujian province, China.

\section{References}

1. ZHOU Y, CHEN C. Single-fed Circularly Polarized Antenna Element with Reduced Coupling for GPS Arrays [J]. Antennas and propagation, IEEE Transactions, pp.1469-1472, Vol.56 (5), May 2008.

2. TOMOYA I, DAISUKE K, KKUNIALI Y, KEIJI Y, AKIRA I, SHUGO F. Circularly Polarized OneSided Directional Slot Antenna with Reflector Metal for 5.8-GHz DSRC Operations [J]. IEEE Antennas and Wireless Propagation Letters, 2014, 13:778-781.

3. FUJITA K, KANEMOTO D , YOSHITOMI K, YOSHIDA K, KANAYA H. UWB Circularly Polarized Planar Antenna on Flexible Substrate[J].IEEE MTT-S Internation,2013,1-3.

4. HANI A. Broad-Band and Circularly Polarized Space-Filling-Based Slot Antennas [J].IEEE Transaction Antennas Propagation, 2005, 53(6):1946-1950. 
5. MA Xiao-liang, HUANG Cheng, PAN Wen-bo, ZHAO Bo, CUI Jian-hua, LUO Xiao-gang. A Dual Circularly Polarized Horn Antenna in $\mathrm{Ku}$-Band Based on Chiral Metamaterial[J]. IEEE Transaction Antennas Propagation,2014,62(4);2307-2311.

6. ZHANG T, ZHANG Y. Single-Layer Wideband Circularly Polarized Patch Antennas for Q-Band Applications [J]. IEEE Transaction Antennas Propagation, 2015,63(10);409-414.

7. WANG LEI, GUO YONGXIN. Wideband modified L-probe fed circularly polarized patch antenna with conical beam radiation pattern [J]. Journal of Electromagnetic Waves and Applications, 2013, 27(27); 969-977.

8. LI Bo, LIAO Shao-wei, and XUE Quan . Omnidirectional Circularly Polarized Antenna Combining Monopole and Loop Radiators [J]. IEEE Antennas and Wireless Propagation Letters, 2013, 12(12):607-610.

9. ZHANG Xue-ying, LIN Shu, WANG Yu-die, LIU Sheng-ying, ZHANG Xin-yue, ZHANG Wen-bin. Broadband Circularly Polarized Antenna with a Ttype Fractal Boundary Wide-slot and a L-shaped Strip [J]. IEEE Microwave Conference Proceeding, 2011, 1-3.

10. ZHANG YQ, YANG L. Dual-band circularly polarized antenna with low observation angle performance enhanced for GNSS applications [J]. Journal of Electromagnetic Waves and Applications, 2014, 28(28); 1131-1141.

11. HE Ye-jun. A Wideband Circularly Polarized CrossDipole Antenna [J]. IEEE Antennas and Wireless Propagation Letters, 2014, 13(1):67-70.

12. RAUT S, PETOSA A. GPS Wideband Circularly Polarized Microstrip Antenna Array [J]. Antenna and Propagation, 2009 EuCAP, 2009, 2990-2993.

13. WANG Can, GE Yuehe. A Novel Design of Broadband Dual-polarized Printed Dipole Antenna for Base Stations [J]. Journal of Huaqiao university, 2014, 35(2):132-135.

14. WANG Can, GE Yue-he. A Novel Broadband Printed Dipole Antenna and Its Application for TDLTE Communications [J]. International Journal of Antennas and Propagation, 2014, 960963, pp.1-7. 